\title{
Perfluorooctanoate suppresses spheroid attachment on endometrial epithelial cells through peroxisome proliferator-activated receptor alpha and down-regulation of Wnt signaling
}

Hilda Tsang ${ }^{\mathrm{a}}$, Tsz-Yan Cheung ${ }^{\mathrm{a}}$, Suranga P Kodithuwakku, ${ }^{\mathrm{a}, \mathrm{c}}$, Joyce Chai ${ }^{\mathrm{a}}$, William SB Yeung $^{\mathrm{a}, \mathrm{b}}$, Chris KC Wong ${ }^{\mathrm{d}, \mathrm{e}}$, and Kai-Fai Lee $\mathrm{e}^{\mathrm{a}, \mathrm{b}, *}$

${ }^{a}$ Department of Obstetrics and Gynaecology, LKS Faculty of Medicine, The University of Hong Kong, Hong Kong

${ }^{\mathrm{b}}$ Centre for Reproduction, Development and Growth, Faculty of Medicine, The University of Hong Kong, Hong Kong

${ }^{c}$ Department of Animal Science, The University of Peradeniya, Peradeniya 20400, Sri Lanka

${ }^{\mathrm{d} C r o u c h e r ~ I n s t i t u t e ~ f o r ~ E n v i r o n m e n t a l ~ S c i e n c e s, ~ F a c u l t y ~ o f ~ S c i e n c e, ~ H o n g ~ K o n g ~ B a p t i s t ~}$ University, Hong Kong

${ }^{e}$ Department of Biology, Faculty of Science, Hong Kong Baptist University, Hong Kong

*Corresponding author at: Department of Obstetrics and Gynaecology, Faculty of Medicine, The University of Hong Kong, Hong Kong. Tel.: +852-2819 9369; Fax: +852-2816 1947; E-mail: ckflee@hku.hk (KFLee) 


\begin{abstract}
Exposure of animals to Perfluorooctanoic acid (PFOA), a surfactant used in emulsion polymerization processes causes early pregnancy loss, delayed growth and development of fetuses. The mechanisms of action are largely unknown. We studied the effect of PFOA on implantation using an in vitro spheroid-endometrial cell co-culture model. PFOA (10-100 $\mu \mathrm{M})$ significantly reduced Jeg-3 spheroid attachment on RL95-2 endometrial cells. PFOA also suppressed $\beta$-catenin expression in Jeg-3 cells. The Wnt agonist Wnt3a stimulated $\beta$-catenin expression in Jeg-3 cells and reversed the PFOA suppression of the spheroid attachment. The putative PFOA receptors (PPAR $\alpha, \beta, \gamma)$ present in both cell lines were not affected by PFOA $(0.01-100 \mu \mathrm{M})$. The PPAR $\alpha$ antagonist MK886 restored the $\beta$-catenin and E-cadherin expression levels in Jeg-3 cells and reversed the suppression of the spheroid attachment caused by PFOA. Taken together, PFOA suppresses spheroid attachment through PPAR $\alpha$ and Wnt signaling pathways via down-regulation of $\beta$-catenin and E-cadherin expression.
\end{abstract}

Key Words: PFOA; Spheroid; Endometrium; Wnt signaling; Attachment; PPAR 


\section{Introduction}

Many natural or man-made chemicals can interfere with the endocrine system leading to adverse health effects in both laboratory animals and wildlife species [1]. For example, 2,3,7,8-tetrachlorodibenzo-p-dioxin (TCDD) can disrupt the morphogenesis of rat pre-implantation embryos [2], reducing the numbers of implanted embryos and live-born pups [3].

Perfluorooctanoic acid (PFOA), a known endocrine disruptor, has been used as a surfactant in emulsion polymerization processes of fluoropolymers for over 50 years. This chemical is present in industrial waste, and has been detected in stain resistant carpets, carpet cleaning liquids, water, food, microwave popcorn bags, and house dust [4]. Moreover, PFOA is persistent in the environment and has been shown to be toxic to laboratory animals and wildlife [5]. Notably, concentrations of PFOA as high as $3.7 \mathrm{ppm}$ have been found in house dust [6]. PFOA can enter the human body by inhalation and ingestion. It binds to proteins in the blood serum and accumulates in various organs including the spleen and liver [7]. PFOA has been detected in the serum of fluorochemical production workers $(691 \mathrm{ng} / \mathrm{mL}$; range, $72-5100 \mathrm{ng} / \mathrm{mL})$, and its half-life in blood is 3.8 years [8]. In various animal studies, PFOA was found to be associated with infertility, birth defects and increased cancer risk [4]. However, direct evidence of how PFOA affects the fertility of animals is lacking. Several acute oral toxicity studies in animals indicate that PFOA causes hepatomegaly and hepatic peroxisome proliferation [9]. Moreover, PFOA exposure increases the risk of liver, testicular and pancreatic tumors, and causes hormonal disruption and immunotoxicity [4]. Perfluorododecanoic acid, a member of the perfluorinated family of compounds, decreased serum testosterone 
levels but increased estradiol levels in adult rats [10]. PFOA modulated serum hormonal effects in rodents causing Leydig cell hyperplasia and adenomas [5], and decreased the expression levels of genes involved in steroidogenesis leading to a reduced serum testosterone level [10].

PFOA binds to the peroxisome proliferator-activated receptors (PPAR $\alpha, \beta / \delta$ and $\gamma$ ) with varying affinities modulating the downstream biological processes [11] including cellular inflammation, reproduction, lipid homeostasis and wound healing [12]. A recent study demonstrated that PPAR $\delta$ interacted with the canonical Wnt signaling pathway in human cholangiocarcinoma cells [13]. Increasing evidence suggests that the Wnt signaling pathway plays very important roles in embryonic development, cell differentiation and implantation $[14,15]$. Activation of Wnt signaling is mediated by binding of Wnt ligands (e.g. Wnt3a) to its receptor allowing accumulation of $\beta$-catenin for gene transcription and downstream biological processes. How PFOA binds to PPAR $\alpha$ and affects the activation of the Wnt signaling pathway for embryo implantation remains largely unknown. We investigated the mechanism of action of PFOA on implantation by studying spheroid attachment using human trophoblastic spheroids (Jeg-3) and endometrial epithelial cells (RL95-2) in a co-culture assay. Because the use of human embryos and primary endometrial epithelial cells is limited, this in vitro co-culture model can mimic the initial embryo (spheroids) attachment process using well-established human cell lines. We used PPAR inhibitors to further elucidate the mechanism of PFOA/PPARs regulation of the canonical Wnt signaling molecules in both Jeg-3 and RL95-2 cells during the spheroid attachment process. 


\section{Materials and methods}

\subsection{Cell culture}

Human choriocarcinoma Jeg-3 (HTB-36, ATCC) and endometrial adenocarcinoma RL95-2 (CRL-1671, ATCC) cells were both cultured at $37^{\circ} \mathrm{C}$ in a humid atmosphere in 5\% $\mathrm{CO}_{2}$. Cells were maintained in DMEM/F12 (Sigma, MO, USA), supplemented with $10 \%$ fetal bovine serum (FBS, Invitrogen, Carlsbad, CA, USA), $2 \mathrm{mM} \mathrm{L-glutamine} \mathrm{and}$ penicillin/streptomycin (100 U/ml and $0.1 \mathrm{mg} / \mathrm{ml})$ (Gibco, NY, USA). For each experiment, $1 \times 10^{5}$ cells were suspended in the cell culture medium and seeded in 12-well tissue culture plates (Iwaki, Japan). PFOA (96\% purity, Sigma) was dissolved in dimethyl sulfoxide (DMSO). The Jeg-3 and RL95-2 cells were then cultured in PFOA-containing culture medium for 24 hrs prior to either Western blotting or spheroid generation for co-culture study. PFOA concentrations ranging from 0.01 to $100 \mu \mathrm{M}$ were prepared in DMSO (0.1\% final concentration) and $0.1 \%$ DMSO was used as the negative control. All treatments were repeated in duplicate at least five times.

\subsection{Protein extraction and Western blotting}

Total protein from cell lysates was dissolved in RIPA solution (1X PBS, $1 \%$ Nonidet P-40, $0.5 \%$ sodium deoxycholate, $0.1 \%$ SDS) containing protease inhibitors. The proteins were separated by SDS-PAGE and transferred onto a PVDF membrane. For Western blotting, antibodies specific for PPAR $\alpha$ (sc-1985, Santa Cruz, CA, USA), PPAR $\beta$ (sc-7197, Santa Cruz), PPAR $\gamma$ (sc-7273, Santa Cruz), $\beta$-catenin (1:2500) (BD Bioscience, CA, USA) and E-cadherin (1:1000) (Abcam, Cambridge, MA, USA) were used. Anti-rabbit, anti-mouse (1:5000) (GE Healthcare, Pittsburgh, PA) or anti-goat antibodies 
(1:5000) (Santa Cruz) were used as the horseradish peroxidase-conjugated secondary antibody. The membranes were visualized by enhanced chemiluminescence (Santa Cruz). To normalize the protein loading, the membranes were stripped and re-blotted with anti- $\beta$-actin antibody (Sigma).

\subsection{Cell proliferation and cell viability assay}

For the cell proliferation assay, $3 \times 10^{3}$ cells were seeded per well in triplicate in 96-well plates. Jeg-3 or RL95-2 cells were cultured for 3 days with different concentrations of PFOA. CyQUANT ${ }^{\circledR}$ Cell Proliferation Assay kit was used to determine the cell number by measuring its DNA content on day 1,2 and 3. Briefly, CyQUANT ${ }^{\circ}$ NF dye reagent was mixed with the $1 \mathrm{X}$ Hank's balanced salt solution (HBSS), and $100 \mu \mathrm{L}$ of this $1 \mathrm{X}$ dye solution was added into each microplate well for DNA binding. After incubating for $1 \mathrm{hr}$ at $37^{\circ} \mathrm{C}$, the fluorescent signal was measured at $535 \mathrm{~nm}$.

For the cell viability assay, $2 \times 10^{5}$ cells were seeded per well in duplicate in six-well plates. Jeg-3 or RL95-2 cells were cultured for 24 hrs with different concentrations of the treatments. The treated cells were trypsinized and the cell suspension was centrifuged for 5 mins at $100 \mathrm{~g}$. The cell pellet was resuspended in $500 \mu \mathrm{l}$ of PBS containing $0.4 \%$ trypan blue. The unstained (viable) and the stained (nonviable) cells were counted using a hemacytometer. The percentage of viable cells was calculated from the total number of cells.

\subsection{Spheroid attachment assay}


The Jeg-3 and RL95-2 cells were cultured at $37^{\circ} \mathrm{C}$ in a humid atmosphere in $5 \%$ $\mathrm{CO}_{2}$ as above. Adhesion of the choriocarcinoma Jeg-3 spheroids on the endometrial RL95-2 cells was quantified using an adhesion assay as previously described [16]. In the co-culture assay, trophoblastic Jeg-3 and endometrial epithelial RL95-2 cells were treated with PFOA (1-100 $\mu \mathrm{M})$ with or without inhibitors of PPAR $\alpha(10 \mu \mathrm{M})$ (MK886, Biomol Res Lab, PA, USA), PPAR $\beta(10 \mu \mathrm{M})(\mathrm{GSK} 0660$, Sigma) and PPAR $\gamma(1 \mu \mathrm{M})(\mathrm{GW} 9662$, Sigma), or 50\% Wnt3a conditioned medium (Wnt3a-CM, 1:1) for 24 hrs before generation of spheroids and co-culture, respectively. The control was the cell differentiation reagent, methotrexate (MTX, $5 \mu \mathrm{M})$ (Hohn et al., 2000) and the negative control was DMSO alone. Spheroids were generated by rotating the trypsinized Jeg-3 cells at $4 \mathrm{~g}$ for $24 \mathrm{hrs}$ without PFOA or PPAR inhibitors. Spheroids with sizes ranging from 60 to $200 \mu \mathrm{m}$ were selected and transferred onto the confluent monolayer of endometrial cells under a dissection microscope, and co-cultured without PFOA or PPAR inhibitors for $1 \mathrm{hr}$ at $37^{\circ} \mathrm{C}$ in a humidified atmosphere in $5 \% \mathrm{CO}_{2}$. Non-adherent spheroids were removed by centrifugation in the medium at $10 \mathrm{~g}$ for $10 \mathrm{mins}$. Attached spheroids were counted under a microscope and the attachment rate was expressed as a percentage of the total number of spheroids transferred (\% adhesion). Images of the cultures were taken using a Nikon Eclipse TE300 inverted microscope (Nikon, Tokyo, Japan).

\subsection{Wnt signaling activation}

Wnt3a conditioned medium (Wnt3a-CM) was obtained from the culture of mouse L cells stably secreting the Wnt3a protein. Briefly, mouse fibroblast L cells over-expressing 
Wnt3a (CRL-2647, ATCC) were cultured in DMEM medium supplemented with $10 \%$ FBS, L-glutamine and penicillin/streptomycin. The conditioned medium was collected after $48 \mathrm{hrs}$ of confluent culture and the expression of Wnt3a protein was confirmed by Western blotting using a specific anti-Wnt3a antibody. The conditioned medium obtained from normal mouse fibroblast L cells was used as the negative control for the spheroid attachment assay. All conditioned media were filter-sterilized and stored at $-20^{\circ} \mathrm{C}$ until used.

\subsection{Statistical analysis}

All results were calculated as the mean \pm standard error of mean (SEM) from at least three independent experiments. All the data were analyzed using the SigmaPlot statistical software (SigmaPlot 11.0; Jandel Scientific, San Rafael, California, USA). The Mann-Whitney U test was used when the data was not normally distributed. A p-value of less than 0.05 was considered to be statistically significant. 


\section{Results}

\subsection{Effect of PFOA on the expression of PPARs in trophoblastic and endometrial cell lines}

The three PPAR isotypes (PPAR $\alpha$, PPAR $\beta$ and PPAR $\gamma$ ) have similar molecular weights but have unique structures associated with the subtype specificity. PFOA (0.01-100 $\mu \mathrm{M})$ did not significantly change the expression of PPAR $\alpha, \operatorname{PPAR} \beta$ and PPAR $\gamma$ in both the Jeg-3 and RL95-2 cells as determined by Western blotting (Figure 1A \& B).

\subsection{PFOA suppressed spheroid attachment onto endometrial cells}

A spheroid-endometrial cell co-culture assay was used to study whether PFOA modulated the attachment of spheroids (blastocyst surrogate) in vitro. The number of attached spheroids was determined after $1 \mathrm{hr}$ of co-culture. A significant decrease in the spheroid attachment rate was observed only when the Jeg-3 cells were treated with PFOA $(100 \mu \mathrm{M})$ (Figure 2). When both Jeg-3 and RL95-2 cells were treated with PFOA (10 and $100 \mu \mathrm{M})$, the spheroid attachment was significantly decreased $(p<0.05$ and $p<0.01$, respectively) (Figure 2). The average viability and proliferation rate of PFOA $(1-100 \mu \mathrm{M})$ treated cells were comparable to the controls as determined by Trypan blue and the CyQUANT cell proliferation assay, respectively (data not shown). MTX (5 $\mu \mathrm{M})$ strongly suppressed spheroid attachment $(p<0.05)$ and was used as the treatment control.

\subsection{Wnt3a reversed the suppressive effect of PFOA on $\beta$-catenin expression and} spheroid attachment in the co-culture model 
The effect of PFOA treatment on $\beta$-catenin and E-cadherin expressions was studied to determine whether PFOA suppresses spheroid attachment through down-regulation of the Wnt signaling pathway. Treatment with PFOA $(10$ and $100 \mu \mathrm{M})$ for 24 hrs strongly suppressed the expression of $\beta$-catenin in the Jeg- 3 cells but not in the RL95-2 cells (Figure 3A \& B). Treatment with PFOA $(100 \mu \mathrm{M})$ also significantly decreased the expression of E-cadherin in the Jeg-3 cells. No observable change in the expression of $\beta$-actin was detected with PFOA treatments.

Wnt3a conditioned medium (Wnt3a-CM) was used to activate the Wnt signaling pathway in the Jeg-3 and RL95-2 cells. Wnt3a-CM (1:1, v/v) alone had no significant effect on cell viability and proliferation (data not shown). PFOA (10 - $100 \mu \mathrm{M})$ strongly suppressed $\beta$-catenin expression in only the Jeg- 3 cells and this suppressive effect was reversed in Wnt3a-CM (Figure 4A). The expression of $\beta$-actin protein remained unchanged in Wnt3a-CM and was used as the loading control. Wnt3a-CM treatment (1:1, $\mathrm{v} / \mathrm{v})$ reversed the suppressive effect of PFOA $(10$ and $100 \mu \mathrm{M})$ on the spheroid attachment compared to the Wnt3a-CM control (Figure 4B). However, Wnt3a-CM itself had a stimulatory effect on $\beta$-catenin expression in Jeg-3 cells and on spheroid attachment in vitro. The MTX $(5 \mu \mathrm{M})$ control strongly suppressed spheroid attachment $(p<0.05)$.

\subsection{Effects of PPAR antagonists on PFOA suppression of the spheroid attachment}

We used PPAR $\alpha$, PPAR $\beta$ and PPAR $\gamma$ antagonists (MK886, GSK0660 and GW9662, respectively) to study the role of PPARs in the PFOA suppression of the $\beta$-catenin expression and spheroid attachment. The concentration of the inhibitors used in this study did not affect the viability and proliferation of the treated cells (data not shown). Western 
blot analysis showed that PFOA strongly suppressed $\beta$-catenin and E-cadherin expressions in Jeg-3 cells, and addition of Wnt3a reversed these suppressive effects. Importantly, treatment of Jeg-3 cells with MK886 $(10 \mu \mathrm{M})$, but not GSK0660 $(10 \mu \mathrm{M})$ or GW9662 $(1 \mu \mathrm{M})$, reversed the suppressive effects of PFOA on the expression of $\beta$-catenin and E-cadherin (Figure 5A). However, PFOA did not affect the expression of $\beta$-catenin and E-cadherin in the RL95-2 cells. We found that the PPAR $\alpha$ inhibitor MK886 $(10 \mu \mathrm{M})$ reversed the PFOA $(100 \mu \mathrm{M})$ suppression of the spheroid attachment (Figure 5B), whereas the PPAR $\gamma$ inhibitor GW9662 $(1 \mu \mathrm{M})$ partially reversed the suppressive effects of PFOA when compared with PFOA treatment group. No significant change was observed when the cells were treated with the PPAR $\beta$ inhibitor GSK0660 $(10 \mu \mathrm{M})$. 


\section{Discussion}

The mechanism of PFOA suppression of trophoblastic spheroid attachment seems to be mainly via the down-regulation of the Wnt signaling pathway in trophoblastic cells. The PFOA suppression of spheroid attachment was reversed by Wnt3a and the PPAR $\alpha$ inhibitor MK886 suggesting the involvement of cross-talk between the Wnt signaling and PPAR pathways in modulating this suppressive effect.

PFOA can activate PPAR $\alpha$ in an in vitro model system. Activation of the PPARs leads to transcription of target genes and modulation of various biological processes including energy homeostasis, lipid metabolism, cell differentiation [17] and pregnancy [18]. In the present study, both the RL95-2 and the Jeg-3 cells expressed PPAR $\alpha$, PPAR $\beta$ and PPAR $\gamma$. Although PFOA $(0.01-100 \mu \mathrm{M})$ did not affect the expression of PPARs and cell viability in Jeg-3 and RL95-2 cells (data not shown), other studies report that PFOA at higher concentrations $(50-500 \mu \mathrm{M})$ can induce cytotoxic effects and change cell cycle profiles in cells in vitro $[19,20]$.

The spheroids-endometrial cells co-culture assay was used to study the attachment process in vitro [21]. Three different treatment groups (Jeg-3 cells, RL95-2 cells, and both cell lines) were used to study the effect of PFOA on the two cell lines. When both cells were treated with PFOA $(10$ and $100 \mu \mathrm{M})$, the spheroid attachment rates decreased significantly. A similar suppressive effect was observed when Jeg-3 cells were treated with PFOA $(100 \mu \mathrm{M})$, suggesting the suppressive effect of PFOA is mainly through trophoblastic cells.

The canonical Wnt signaling pathway regulates embryo implantation and early embryonic development $[15,22]$. PFOA strongly suppresses $\beta$-catenin and E-cadherin 
expression in the Jeg-3 cells, but how these changes affect spheroid attachment remains largely unknown. The expression of endometrial E-cadherin and $\beta$-catenin are higher in healthy fertile women, and impaired down-regulation of endometrial E-cadherin and $\beta$-catenin expression during the window of implantation is associated with infertility in patients with endometriosis [23]. In contrast, up-regulation of $\beta$-catenin in the apical membrane of epithelial cells at the implantation sites was observed in mice [24]. In line with these observations, we found that Wnt3a-CM up-regulated $\beta$-catenin expression in Jeg-3 cells and stimulated spheroid attachment. Similarly, addition of the Wnt agonist Wnt3a restored $\beta$-catenin expression in Jeg-3 cells and reversed the suppressed spheroid attachment caused by PFOA. These observations relating to spheroids attachment are in agreement with our previous findings on trophoblastic (BeWo) and endometrial (RL95-2) cells treated with another endocrine disruptor, TCDD [25], or oviductal epithelial (OE-E6/E7) cells treated with a Wnt antagonist, Olfm [26].

To determine whether PFOA interacts with PPARs to affect spheroid attachment, we used three PPAR antagonists (MK886, GSK0660 and GW9662). MK886 inhibits PPAR $\alpha$ through a non-competitive mechanism that prevents conformational change during the active-complex formation [27]. GSK0660 is a potent PPAR $\beta / \delta$ antagonist [28] and GW9662 covalently modifies the cysteine residue at the binding site of PPAR $\gamma$ [29]. The concentrations of the PPARs antagonists used were specific for inhibiting the different PPAR receptors $[28,30,31]$. However, the effect of the specific antagonist on development and pregnancy outcome in animals remains largely unknown. Our findings showed that MK886 reversed the PFOA-induced suppression of the spheroid attachment, but GSK0660 had no reversing effect, and GW9662 could only partially reverse the effects 
of PFOA $(100 \mu \mathrm{M})$ when compared with PFOA treated group. This suggests that PFOA exerts its effect mainly through the PPAR $\alpha$ pathway. Although mice deficient in PPAR $\alpha$ are not associated with early pregnancy lost, PPAR $\alpha$ is required for PFOA-induced postnatal lethality [32]. Treatment with a lower concentration of PFOA $(10 \mu \mathrm{M})$ in both the Jeg-3 and RL95-2 cells affected spheroid attachment, but PFOA (10 $\mu \mathrm{M})$ with RL95-2 cells alone had no effect on $\beta$-catenin expression and spheroid attachment. This suggests that PFOA may affect the expression of other molecule(s) that are important for spheroid and endometrial cells interaction in vitro.

Our results show that PFOA suppressed spheroid attachment on endometrial epithelial cells, which is mediated by $\operatorname{PPAR} \alpha$ and suppression of the Wnt signaling pathway via down-regulation of $\beta$-catenin and E-cadherin expression. Although our experimental concentrations were 100-fold higher, the current findings suggest that the PFOA serum levels $(72-5,100 \mathrm{ng} / \mathrm{ml}$ or $0.17-12 \mu \mathrm{M})$ could potentially have detrimental effects on spheroid attachment on endometrial cells in vivo. PFOA may, therefore, disrupt cell-cell adhesion important for the initial embryo attachment in vivo. The combined effect of PFOA with other endocrine disruptors (e.g. TCDD, BPA) [25] on human body should not be underestimated.

\section{Conflict of interest}

The author declares that there is no conflict of interest.

\section{Acknowledgments}

This work was supported in part by a CRCG grant, HKU to KFL and a 
Collaborative Research Fund (HKBU 1/CRF/08), University Grants Committee to CKCW. The revised manuscript was edited by Dr Edmund Lane. 


\section{References}

[1] Diamanti-Kandarakis E, Bourguignon JP, Giudice LC, Hauser R, Prins GS, Soto AM, Zoeller RT, Gore AC. Endocrine-disrupting chemicals: an Endocrine Society scientific statement. Endocr Rev 2009;30:293-342.

[2] Hutt KJ, Shi Z, Albertini DF, Petroff BK. The environmental toxicant 2,3,7,8-tetrachlorodibenzo-p-dioxin disrupts morphogenesis of the rat pre-implantation embryo. BMC Dev Biol 2008;8:1.

[3] Wolf CJ, Ostby JS, Gray LE Jr. Gestational exposure to 2,3,7,8-tetrachlorodibenzo-p-dioxin (TCDD) severely alters reproductive function of female hamster offspring. Toxicol Sci 1999;51:259-64.

[4] Kennedy GL Jr, Butenhoff JL, Olsen GW, O'Connor JC, Seaca, AM, Perkins RG, Biegel LB, Murphy SR, Farrar DG. The toxicology of perfluorooctanoate. Crit Rev Toxicol 2004;34:351-84.

[5] Palkar PS, Anderson CR, Ferry CH, Gonzalez FJ, Peters JM. Effect of prenatal peroxisome proliferator-activated receptor alpha (PPARalpha) agonism on postnatal development. Toxicology 2010;276:79-84.

[6] Shoeib M, Harner T, Ikonomou M, Kannan K. Indoor and outdoor air concentrations and phase partitioning of perfluoroalkyl sulfonamides and polybrominated diphenyl ethers. Environ Sci Technol 2004;38:1313-20.

[7] Yeung LWY, So MK, Jiang GB, Taniyasu S, Yamashita N, Song MY, Wu YN, Li JG, Giesy JP, Guruge KS, Lam PKS. Perfluorooctanesulfonate and related fluorochemicals in human blood samples from China. Environ Sci Technol 2006;40:715-20.

[8] Olsen GW, Burris JM, Ehresman DJ, Froehlich JW, Seacat AM, Butenhoff JL, Zobel LR. Half-life of serum elimination of perfluorooctanesulfonate, perfluorohexanesulfonate, and perfluorooctanoate in retired fluorochemical production workers. Environ Health Perspect 2007;115:1298-305.

[9] Kudo N, Suzuki-Nakajima E, Mitsumoto A, Kawashima Y. Responses of the liver to perfluorinated fatty acids with different carbon chain length in male and female mice: In relation to induction of hepatomegaly, peroxisomal beta-oxidation and microsomal 1-acylglycerophosphocholine acyltransferase. Biol Pharm Bull 
2006;29:1952-7.

[10] Shi Z, Zhang H, Liu Y, Xu M, Dai J. Alterations in gene expression and testosterone synthesis in the testes of male rats exposed to perfluorododecanoic acid. Toxicol Sci 2007;98:206-15.

[11] Takacs ML, Abbott BD. Activation of mouse and human peroxisome proliferator-activated receptors (alpha, beta/delta, gamma) by perfluorooctanoic acid and perfluorooctane sulfonate. Toxicol Sci 2007;95:108-17.

[12] Abbott BD. Review of the expression of peroxisome proliferator-activated receptors alpha (PPAR alpha), beta (PPAR beta), and gamma (PPAR gamma) in rodent and human development. Reprod Toxicol 2009;27:246-57.

[13] Han C, Lim K, Xu LH, Li GY, Wu T. Regulation of Wnt/beta-catenin pathway by cPLA(2)alpha and PPAR delta. J Cell Biochem 2008;105:534-45.

[14] Widelitz R. Wnt signaling through canonical and non-canonical pathways: Recent progress. Growth Factors 2005;23:111-6.

[15] Xie H, Tranguch S, Jia X, Zhang H, Das SK, Dey SK, Kuo CJ, Wang H. Inactivation of nuclear Wnt-beta-catenin signaling limits blastocyst competency for implantation. Development 2008;135:717-27.

[16] Liu Y, Kodithuwakku SP, Ng PY, Chai J, Ng EH, Yeung WS, Ho PC, Lee KF. Excessive ovarian stimulation up-regulates the Wnt-signaling molecule DKK1 in human endometrium and may affect implantation: an in vitro co-culture study. Hum Reprod 2010;25:479-90.

[17] Escher P, Wahli W. Peroxisome proliferator-activated receptors: insight into multiple cellular functions. Mutat Res 2000;448:121-38.

[18] Matsuo H, Strauss JF. Peroxisome Proliferators and Retinoids Affect Jeg-3 Choriocarcinoma Cell-Function. Endocrinology 1994;135:1135-45.

[19] Fernández Freire P, Pérez Martin JM, Herrero O, Peropadre A, de la Peña E, Hazen MJ. In vitro assessment of the cytotoxic and mutagenic potential of perfluorooctanoic acid. Toxicology in Vitro 2008;22:1228-33.

[20] Watanabe MX, Jones SP, Iwata H, Kim EY, Kennedy SW. Effects of co-exposure to 2,3,7,8-tetrachlorodibenzo-p-dioxin and perfluorooctane sulfonate or perfluorooctanoic acid on expression of cytochrome P450 isoforms in chicken 
(Gallus gallus) embryo hepatocyte cultures. Comp Biochem Physiol C Toxicol Pharmacol 2009;149:605-12.

[21] Hohn HP, Linke M, Denker HW. Adhesion of trophoblast to uterine epithelium as related to the state of trophoblast differentiation: In vitro studies using cell lines. Mol Reprod Dev 2000;57:135-45.

[22] Mohamed OA, Jonnaert M, Labelle-Dumais C, Kuroda K, Clarke H, Dufort D. Uterine Wnt/beta-catenin signaling is required for implantation. Proc Natl Acad Sci USA 2005;102:8579-84.

[23] Matsuzaki S, Darcha C, Maleysson E, Canis M, Mage G. Impaired Down-Regulation of E-Cadherin and beta-Catenin Protein Expression in Endometrial Epithelial Cells in the Mid-Secretory Endometrium of Infertile Patients with Endometriosis. J Clin Endocr Metab 2010;95:3437-45.

[24] Jha RK, Titus S, Saxena D, Kumar PG, Laloraya M. Profiling of E-cadherin, beta-catenin and $\mathrm{Ca}(2+)$ in embryo-uterine interactions at implantation. FEBS Lett 2006;580:5653-60.

[25] Tsang H, Cheung TY, Kodithuwakku SP, Chai J, Yeung WS, Wong CK, Lee KF. 2,3,7,8-Tetrachlorodibenzo-p-dioxin (TCDD) suppresses spheroids attachment on endometrial epithelial cells through the down-regulation of the Wnt-signaling pathway. Reprod Toxicol 2012;33:60-6.

[26] Kodithuwakku SP, Pang RT, Ng EH, Cheung AN, Horne AW, Ho PC, Yeung WS, Lee KF. Wnt activation downregulates olfactomedin-1 in Fallopian tubal epithelial cells: a microenvironment predisposed to tubal ectopic pregnancy. Lab Invest 2012;92:256-64.

[27] Kehrer JP, Biswal SS, La E, Thuillier P, Datta K, Fischer SM, Heuvel JPV. Inhibition of peroxisome-proliferator-activated receptor (PPAR) alpha by MK886. Biochem J 2001;356:899-906.

[28] Billin AN, Shearer BG, Steger DJ, Way JM, Stanley TB, Lobe DC, Grillot DA, Iannone MA, Lazar MA, Willson TM. Identification and characterization of a selective peroxisome proliferator-activated receptor beta/delta (NR1C2) antagonist. Mol Endocrinol 2008;22:523-9.

[29] Jingami H, Shiraki T, Kamiya N, Shiki S, Kodama TS, Kakizuka A. 
Alpha,beta-unsaturated ketone is a core moiety of natural ligands for covalent binding to peroxisome proliferator-activated receptor gamma. J Biol Chem 2005;280:14145-53.

[30] Dubrac S, Stoitzner P, Pirkebner D, Elentner A, Schoonjans K, Auwerx J, Saeland S, Hengster P, Fritsch P, Romani N, Schmuth M. Peroxisome proliferator-activated receptor-alpha activation inhibits Langerhans cell function. J Immunol 2007;178:4362-72.

[31] Wang PH, Yu YH, Lin EC, Wu SC, Cheng WTK,. Mersmann HJ, Ding ST. Docosahexaenoic acid regulates adipogenic genes in myoblasts via porcine peroxisome proliferator-activated receptor gamma. J Anim Sci 2008;86:3385-392.

[32] Abbott BD, Wolf CJ, Schmid JE, Das KP, Zehr RD, Helfant L, Nakayama S, Lindstrom AB, Strynar MJ, Lau C. Perfluorooctanoic acid induced developmental toxicity in the mouse is dependent on expression of peroxisome proliferator activated receptor-alpha. Toxicol Sci 2007;98:571-81. 


\section{Figure legend}

Figure 1 Effects of PFOA on PPAR expression. (A) The expression of peroxisome proliferator-activated receptors (PPAR $\alpha, \beta$ and $\gamma$ ) in human choriocarcinoma Jeg-3 and endometrial epithelial RL95-2 cells treated with PFOA $(0.01-100 \mu \mathrm{M})$ for $24 \mathrm{hrs}$. PFOA $(0.01-100 \mu \mathrm{M})$ treatment did not significantly alter the expression of PPARs proteins in Jeg-3 and RL95-2 cells. The expression of $\beta$-actin was used as the loading control. (B) The expressions of PPAR $\alpha, \beta$ and $\gamma$ were quantified relative to $\beta$-actin expression in Jeg-3 and RL95-2 cells.

Figure 2 Effects of PFOA on Jeg-3 spheroids (blastocyst surrogate) and RL95-2 (endometrial epithelial cells) cell attachment assay. (Upper panel) PFOA (100 $\mu \mathrm{M})$ treated Jeg-3 cells suppressed spheroid attachment. (Middle panel) PFOA (1 - $100 \mu \mathrm{M})$ treated RL95-2 cells showed no observable changes to the spheroid attachment. (Bottom panel) PFOA (10 and $100 \mu \mathrm{M})$ strongly suppressed Jeg-3 spheroids attachment on RL95-2 cells. The numbers in the bar represent the total number of attached spheroids over the total number of spheroids added. ${ }^{*} p<0.05,{ }^{*} p<0.005$ and ${ }^{*} * * p<0.001$ denote significant differences from the untreated control (Con).

Figure 3 Effects of PFOA on $\beta$-catenin and E-cadherin expressions in Jeg-3 and RL95-2 cells. (A) Jeg-3 and RL95-2 cells were treated with PFOA (0.01 - $100 \mu \mathrm{M})$ for 24 hrs. The expression of $\beta$-catenin and E-cadherin were reduced in Jeg-3 but not in RL95-2 cells. No change was observed in $\beta$-actin expression. (B) The expressions of 
$\beta$-catenin and E-cadherin were quantified relative to $\beta$-actin expression in Jeg-3 and RL95-2 cells. ${ }^{*} p<0.05$ and ${ }^{* *} p<0.01$ denote significant differences from the control.

Figure 4 Wnt3a restored the suppressive effect of PFOA on $\beta$-catenin expression and spheroid attachment. (A) Wnt3a conditioned medium (Wnt3a-CM; 1:1, v/v) reversed the suppressive effect of PFOA on $\beta$-catenin expression in Jeg-3 cells but not in RL95-2 cells. No change was observed in $\beta$-actin expression. (B) Wnt3a-CM (1:1, v/v) nullified the suppressive effect of PFOA on Jeg-3 spheroid attachment onto RL95-2 cells, but also stimulated spheroid attachment in the absence of PFOA. ${ }^{*} p<0.05,{ }^{*} p<0.005$ and ${ }^{* * *} p<0.001$ denote significant differences from the control.

Figure 5 PPAR antagonists reversed the suppressive effect of PFOA on $\beta$-catenin and E-cadherin expression and spheroid attachment. (A) Western blots of Jeg-3 and RL95-2 cells treated with PFOA $(100 \mu \mathrm{M})$, Wnt3a-CM (Wnt3a) and PPAR inhibitors (MK886, GSK0660 and GW9662). PFOA suppressed $\beta$-catenin and E-cadherin expression; whereas Wnt3a induced $\beta$-catenin expression in the Jeg-3 cells. Addition of MK886, but not GSK0660 or GW9662, reversed the suppressive effect of PFOA on $\beta$-catenin and E-cadherin expressions in the Jeg-3 cells. No significant change in $\beta$-catenin and E-cadherin expressions was found in RL95-2 cells. $\beta$-actin was used as the loading control. (B) PFOA (100 $\mu \mathrm{M})$ suppressed Jeg-3 spheroid attached on RL95-2 cells. The suppressive effect could be nullified by treating the cells with MK886 (10 $\mu \mathrm{M})$ but not GSK0660 (10 $\mu \mathrm{M})$. The suppressive effect could be partially nullified by GW9662 (1 $\mu \mathrm{M})$. MK886, GSK0660 or GW9662 alone had no effect on spheroid attachment. MTX 
$(5 \mu \mathrm{M})$ strongly suppressed $(p<0.001)$ spheroid attachment and was used as a positive control. ${ }^{*} p<0.05,{ }^{* *} p<0.005$ and ${ }^{* * *} p<0.001$ denote significant differences from the control. 
Figure 1

A
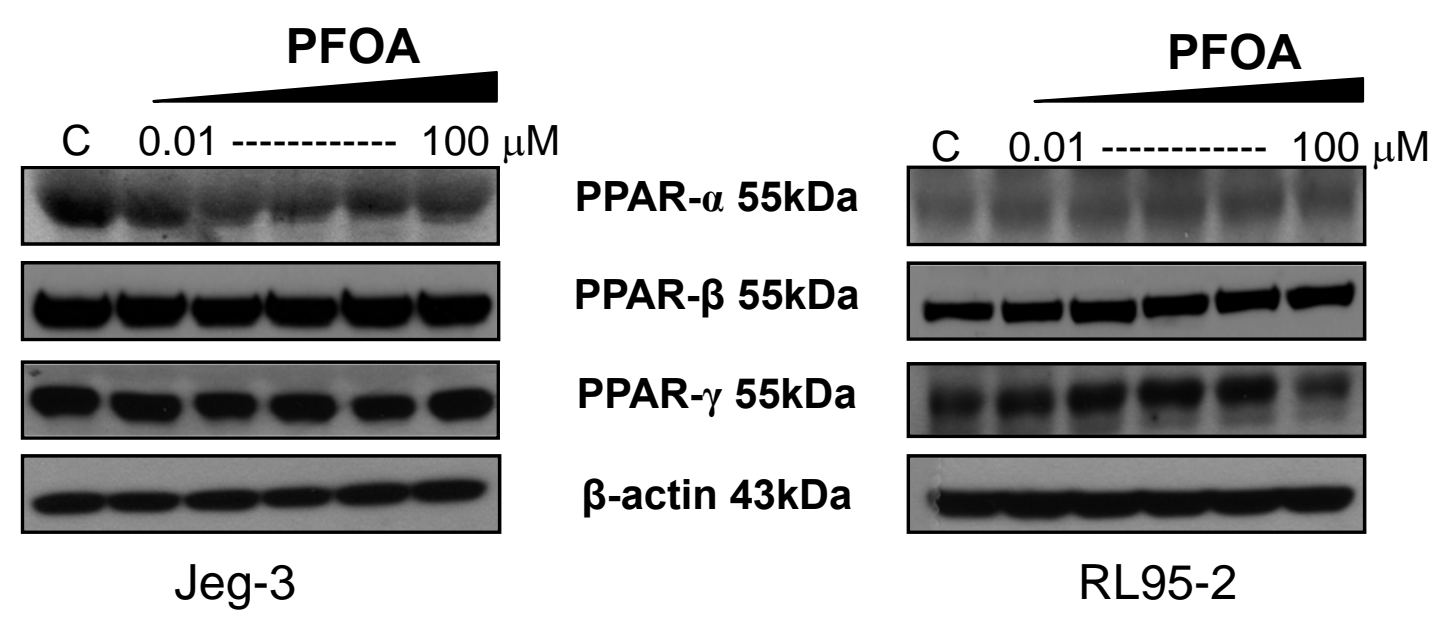

B

Jeg-3
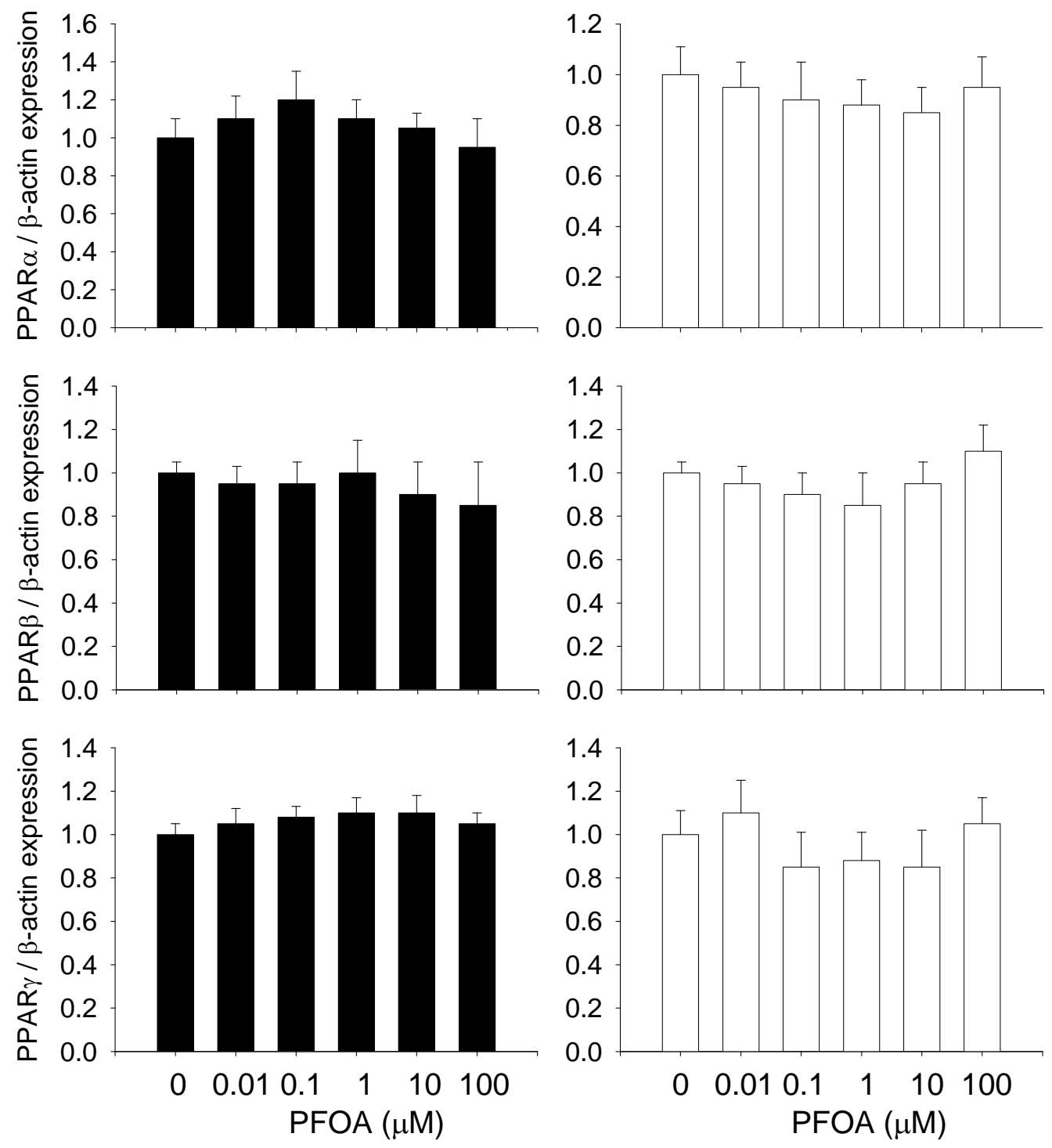
Figure 2

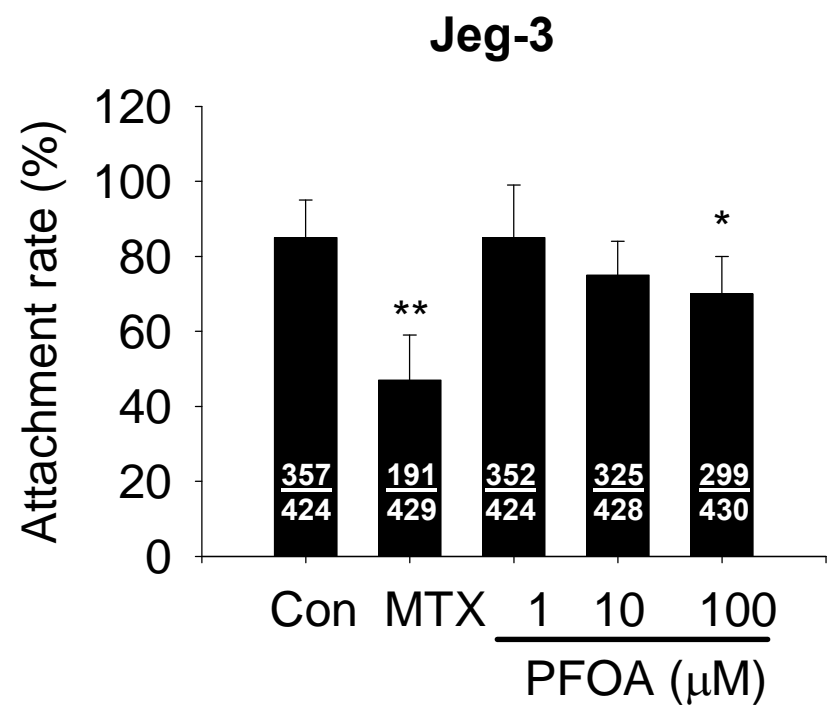

RL95-2

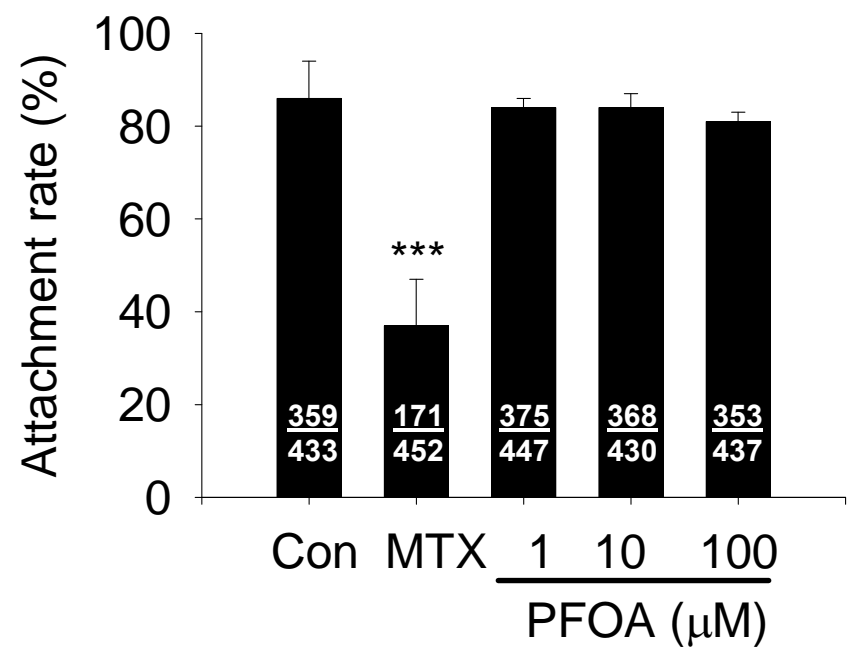

Jeg-3/RL95-2

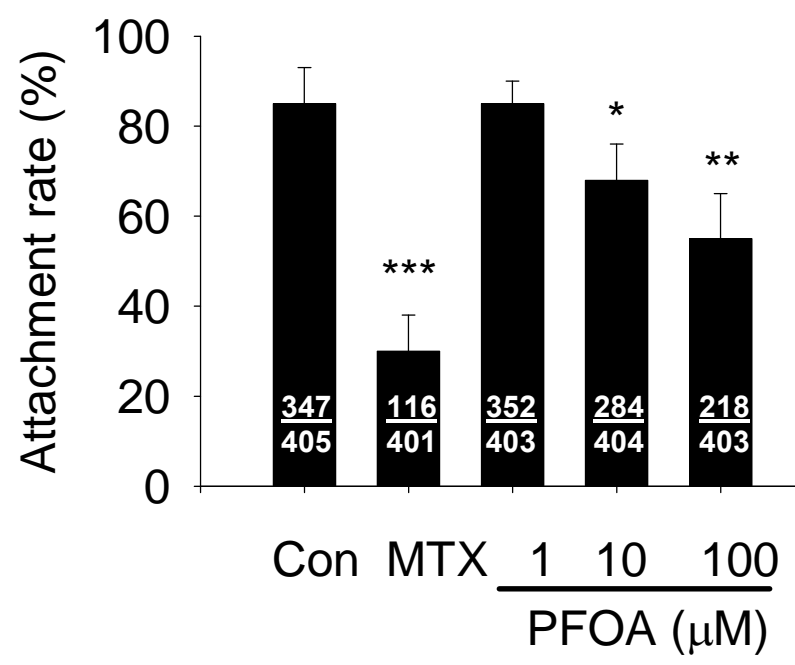


Figure 3

A
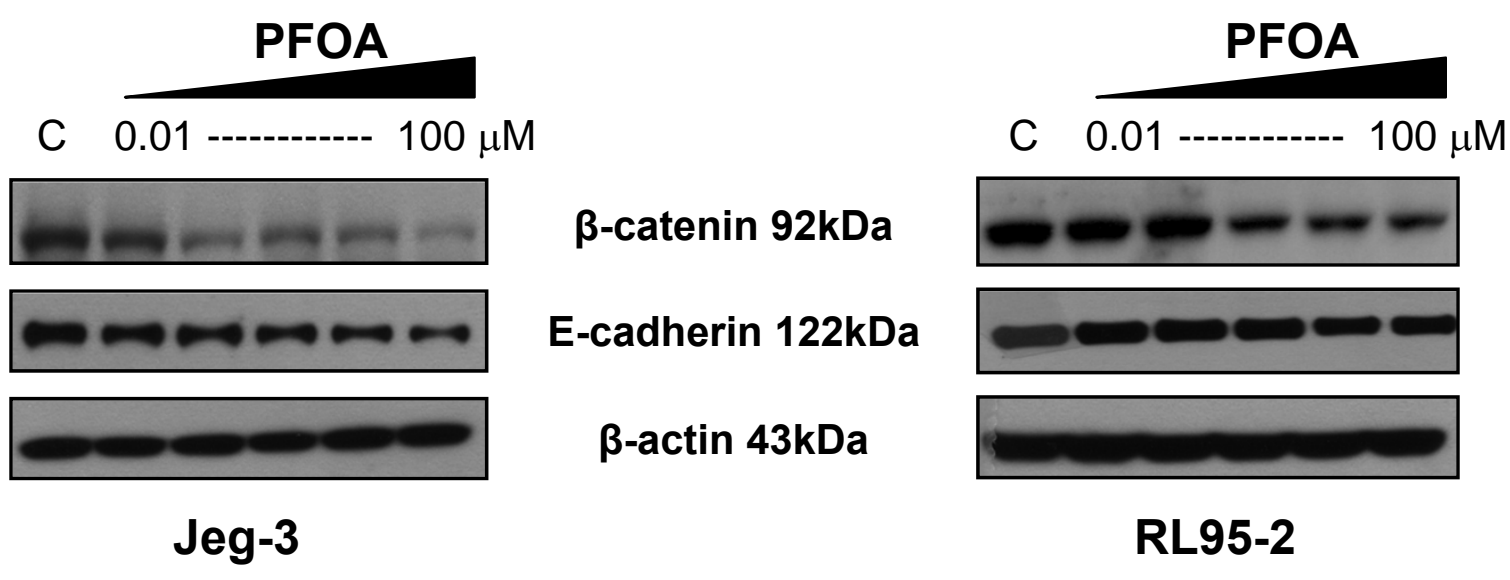

B
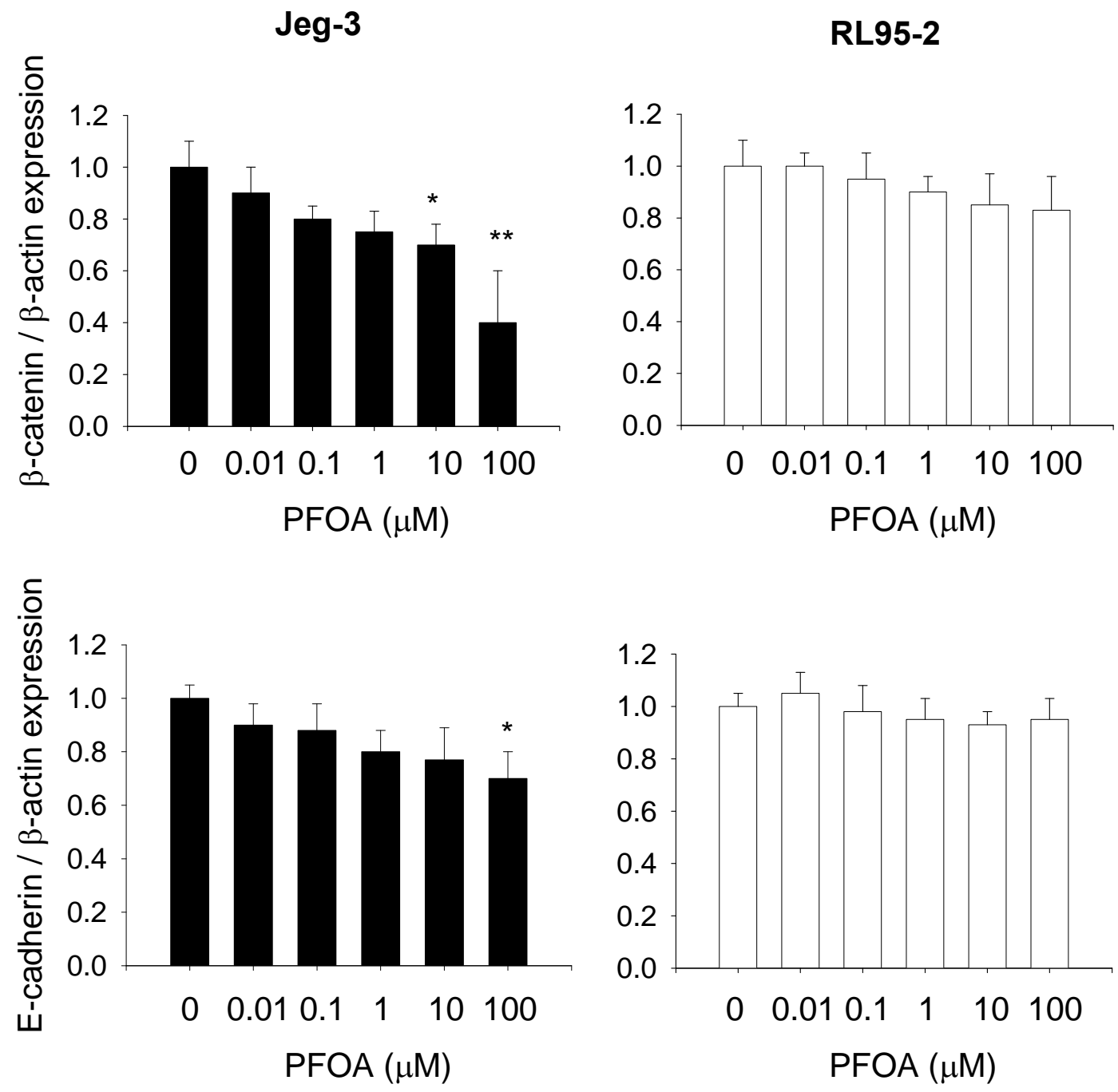
Figure 4

A

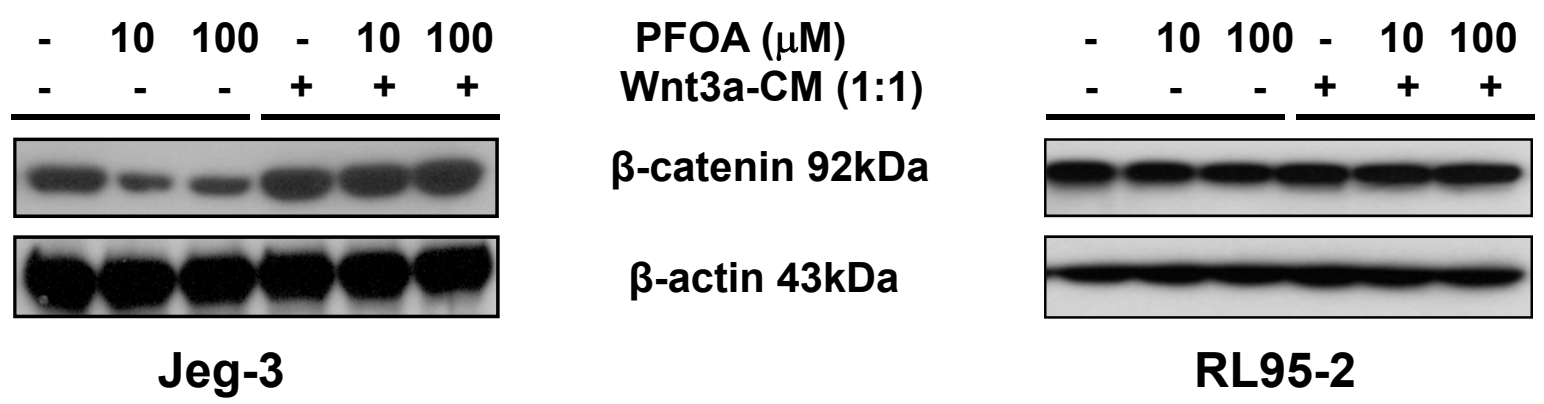

B

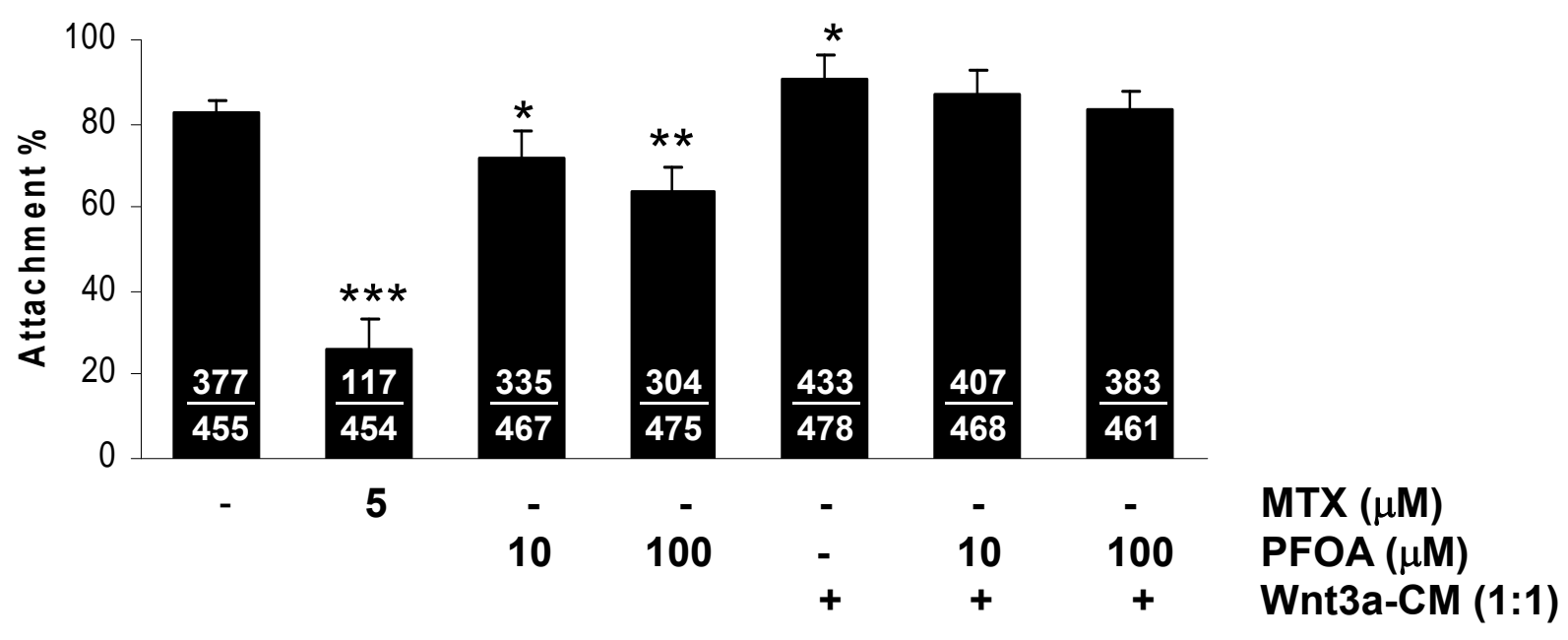


Figure 5

A

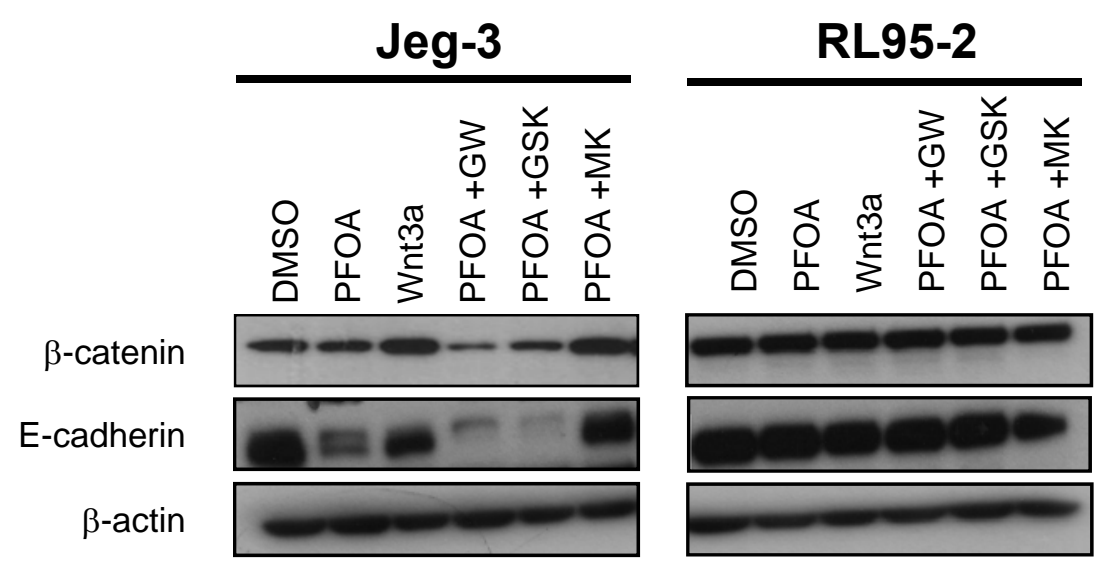

B

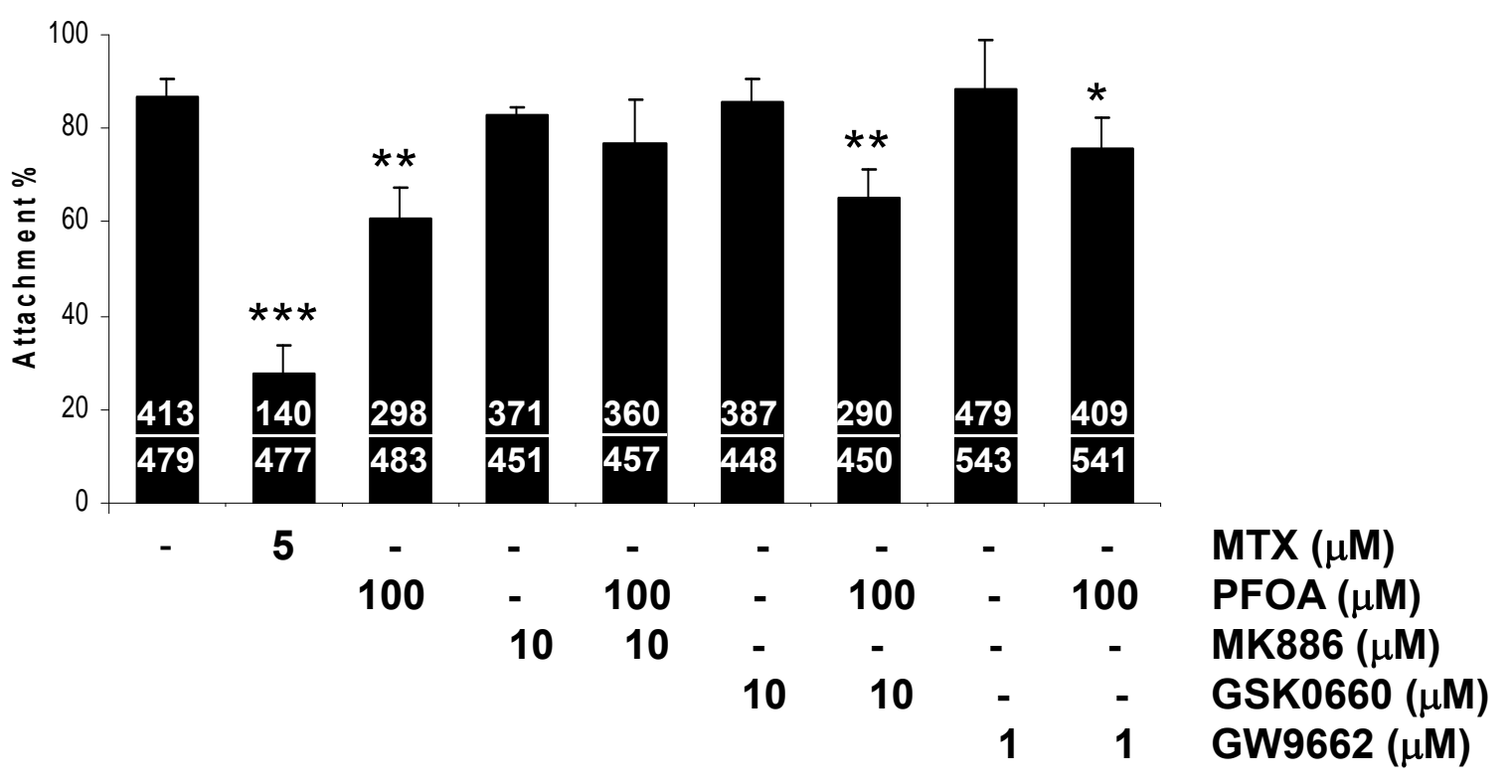

